Check for updates

Cite this: Mater. Adv., 2021,

2, 1294

Received 5th December 2020, Accepted 12th January 2021

DOI: 10.1039/d0ma00955e

rsc.li/materials-advances

\title{
Atomic layer deposition of nano-scale molybdenum sulfide within a metal-organic framework for highly efficient hydrodesulfurization $\dagger$
}

\author{
Lei Yu, ${ }^{\text {ab }}$ Wen-Gang Cui, ${ }^{\text {ab }}$ Qiang Zhang, ${ }^{\text {ab }}$ Zhuo-Fei Li, ${ }^{\text {ab }}$ Yan Shen $^{\text {ab }}$ and \\ Tong-Liang $\mathrm{Hu}(\mathrm{D})$ *abc
}

\begin{abstract}
Molybdenum sulfide $\left(\mathrm{MoS}_{2}\right)$ exhibits extremely encouraging performance in applications of hydrodesulfurization (HDS). However, due to its low active sites, incomplete sulfidation and accounting for more than $70 \%$ of the quality of the supported catalyst for alumina, without playing a catalytic role, the $\gamma-\mathrm{Al}_{2} \mathrm{O}_{3}$ supported catalyst has low reactivity and high cost. Here, we selectively functionalized $\mathrm{MoS}_{2}$ on the nodes of a metal-organic framework (MOF, NU-1000) through atomic layer deposition (ALD) and explored its catalytic performance in the HDS of dibenzothiophene. The AIM-60 (AIM = ALD in a metal-organic framework) catalyst obtained was characterized by $\mathrm{X}$-ray diffraction (XRD), $\mathrm{N}_{2}$ adsorption-desorption, thermogravimetric analysis (TG), $X$-ray photoelectron spectroscopy (XPS), Fourier transform infrared spectroscopy (FT-IR), and scanning and transmission electron microscopy (SEM and TEM). The conversion rate of the AIM-60 material is $86.7 \%$ at $250{ }^{\circ} \mathrm{C}$ and $3 \mathrm{MPa}$, which is much better than that of traditional $\mathrm{MoS}_{2} / \gamma-\mathrm{Al}_{2} \mathrm{O}_{3}$ (8.6\%) with the same loading. In addition, the AIM-60 catalyst shows a preference for the direct desulfurization (DDS) pathway, and it can directly convert dibenzothiophene to biphenyl, with excellent stability in real-life tests. The results indicate that AIM-60 with high activity and high stability represents a new class of HDS catalyst.
\end{abstract}

\section{Introduction}

Over the years, the burning of sulfur compounds has accelerated environmental degradation and had a serious impact on human life. ${ }^{1,2}$ Desulfurization has become one of the major problems for the petroleum industry, especially in the context of strict legislation and increasing environmental awareness. ${ }^{3}$ In China, the United States and other countries and regions, the sulfur content in fuel is strictly limited to less than $10 \mu \mathrm{g} \mathrm{g}^{-1} \cdot \cdot^{4-7}$ Although some methods, such as oxidative desulfurization, adsorption desulfurization, and biodesulfurization have been reported in the literature, hydrodesulfurization (HDS) is still the most important method in the petroleum industry. ${ }^{8-10}$ Nevertheless, the key point is the development of an efficient hydrodesulfurization catalyst. In terms of HDS

\footnotetext{
${ }^{a}$ School of Materials Science and Engineering, Tianjin Key Laboratory of Metal and Molecule-Based Material Chemistry, National Institute for Advanced Materials, Nankai University, Tianjin 300350, China. E-mail: tlhu@nankai.edu.cn

${ }^{b}$ Tianjin Key Lab for Rare Earth Materials and Applications, Nankai University, Tianjin 300350, China

${ }^{c}$ State Key Laboratory of Coordination Chemistry, Nanjing University, Nanjing 210023, China

† Electronic supplementary information (ESI) available. See DOI: 10.1039/ d0ma00955e
}

catalysts, Co-Mo-S or Ni-W-S loaded on $\gamma$-alumina is one of the most common catalytic systems, in which, generally, cobalt or nickel act as an auxiliary agent. ${ }^{11-15}$ At the same time, alumina accounts for more than $70 \%$ of the quality of the supported catalyst, without playing a catalytic role. ${ }^{16}$ Therefore, in the search for new methods to achieve good dispersion of active metals, we turned to metal-organic framework materials (MOFs), ${ }^{17-20}$ as a novel catalytic material consisting of metalinorganic nodes and organic linkers, which have aroused great interest in other applications. ${ }^{21-23} \mathrm{~A}$ small portion of them exhibit unique thermal stability and relatively large pore size, which are critical for catalytic and energy conversion applications. ${ }^{24,25}$ There is increasing interest in the use of atomic layer deposition (ALD) to incorporate single-site metal clusters into MOF. ${ }^{26-29}$ Of particular interest is the introduction of metal atoms into nanomaterials at the atomic scale to prepare materials with a uniform distribution of active sites. However, due to the instability of most MOFs in a hydrogen sulfide atmosphere, the fixation of metal sulfides on MOFs is rare. $^{30,31}$ In recent years, zirconium-based MOF NU-1000 has attracted a lot of attention because of its strong resistance to hydrogen sulfide. ${ }^{32} \mathrm{NU}-1000$ is especially suitable for use as a carrier for metal sulfide deposition for the following reasons: (1) the available hydroxy/water ligands on the $\mathrm{Zr}_{6}$ node in 
NU-1000 can be combined with an ALD precursor, ${ }^{33-36}$ (2) large mesoporous channels can satisfy the diffusion of ALD precursors and reaction substrates and promote the effective binding of catalysts and substrates, ${ }^{37}(3)$ high stability under the reaction conditions required for desulfurization applications, ${ }^{32}(4)$ with high specific surface area, more active centers could be obtained, and the adjustability of the structure may provide synergistic catalytic activities.

In order to develop a high-performance hydrodesulfurization catalyst, herein we incorporate a highly stable and dispersed molybdenum disulfide within NU-1000 by the ALD method. The HDS of dibenzothiophene (DBT) was selected as the model reaction to prove the special properties of asprepared AIM- $X(X=30,40,50,60,70,80,90,100)$, where $X$ represents the number of ALD cycles. The physicochemical properties and hydrodesulfurization activity of these catalysts were thoroughly studied. The conversion rate of AIM-60 is $86.7 \%$ at $250{ }^{\circ} \mathrm{C}$ and $3 \mathrm{MPa}$, which is much higher than that of $\mathrm{MoS}_{2} / \gamma-\mathrm{Al}_{2} \mathrm{O}_{3}$, and AIM-60 prefers the direct desulfurization path. In addition, the conversion rate remains basically unchanged after $20 \mathrm{~h}$ of circulation.

\section{Experimental section}

\section{Materials}

All reagents are analytically pure and were used directly without further purification. Zirconium tetrachloride $\left(\mathrm{ZrCl}_{4}\right)$, dibenzothiophene $\left(\mathrm{C}_{12} \mathrm{H}_{8} \mathrm{~S}\right)$, 4,6-dimethyldibenzothiophene $\left(\mathrm{C}_{14} \mathrm{H}_{12} \mathrm{~S}\right)$, hexacarbonyl molybdenum $\left(\mathrm{Mo}(\mathrm{CO})_{6}\right)$, benzoic acid $\left(\mathrm{C}_{6} \mathrm{H}_{5} \mathrm{COOH}\right)$, 1,3,6,8-terakis( $p$-benzoic acid)-pyrene ( $\left.\mathrm{H}_{4} \mathrm{TBAPy}\right)$, ammonium molybdate $\left(\left(\mathrm{NH}_{4}\right)_{6} \mathrm{Mo}_{7} \mathrm{O}_{24} \cdot 4 \mathrm{H}_{2} \mathrm{O}\right)$, acetone $\left(\mathrm{CH}_{3} \mathrm{COCH}_{3}\right)$, hydrochloric acid $(\mathrm{HCl})$, hexane $\left(\mathrm{CH}_{3}\left(\mathrm{CH}_{2}\right)_{4} \mathrm{CH}_{3}\right)$ (chromatographic pure) and ethanol $\left(\mathrm{C}_{2} \mathrm{H}_{5} \mathrm{OH}\right)$ were purchased from SigmaAldrich. The gases employed were $\mathrm{N}_{2}, 2 \% \mathrm{H}_{2} \mathrm{~S}$ in $\mathrm{N}_{2}$, and $10 \%$ $\mathrm{H}_{2}$ in $\mathrm{Ar}$.

\section{Synthesis of NU-1000}

NU-1000 was synthesized and activated according to previous work with slight modification. ${ }^{34,36}$ In short, an autoclave (100 $\mathrm{mL}$ ) was charged with $\mathrm{ZrCl}_{4}(420 \mathrm{mg}, 1.80 \mathrm{mmol})$, benzoic acid $(16.2 \mathrm{~g}, 132.6 \mathrm{mmol})$ and $48 \mathrm{~mL}$ of $N, N$-dimethylformamide (DMF), which was sonicated for $30 \mathrm{~min}$. The clear solution was subsequently incubated in an $80{ }^{\circ} \mathrm{C}$ oven for $1 \mathrm{~h}$. After cooling down to room temperature, $\mathrm{H}_{4}$ TBAPy $(240 \mathrm{mg}, 0.36 \mathrm{mmol}$ ) was added to this solution and the yellow suspension was sonicated for $20 \mathrm{~min}$, then placed in a $120^{\circ} \mathrm{C}$ oven for $48 \mathrm{~h}$. Single yellow crystals were isolated via centrifugation (9000 rpm, $5 \mathrm{~min}$ ) and washed with DMF twice. Then they were mixed with $72 \mathrm{~mL}$ of DMF and $3 \mathrm{~mL}$ of $8 \mathrm{M} \mathrm{HCl}$. This mixture was heated in a $100{ }^{\circ} \mathrm{C}$ oven for $24 \mathrm{~h}$. After cooling down to room temperature, the sample was washed twice with DMF to remove $\mathrm{HCl}$ impurity and washed with acetone twice and then soaked in acetone overnight. Before using, NU-1000 was filtered and activated at $80{ }^{\circ} \mathrm{C}$ under vacuum for $12 \mathrm{~h}$.

\section{Synthesis of AIM-X}

ALD of $\mathrm{MoS}_{2}$ was conducted on an ALD instrument (Fig. S1, $\mathrm{ESI} \dagger$ ). In a typical procedure, activated NU-1000 (about $80 \mathrm{mg}$ ) was allowed to equilibrate for $2 \mathrm{~h}$ in the ALD sample chamber

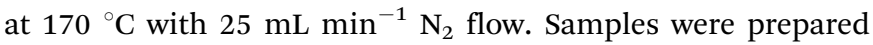
with 30, 40, 50, 60, 70, 80, 90, 100 ALD cycles, where each ALD cycle consisted of multiple Mo precursor pulses, followed by multiple $\mathrm{H}_{2} \mathrm{~S}$ pulses. The prepared samples were recorded as AIM-30, AIM-40, AIM-50, AIM-60, AIM-70, AIM-80, AIM-90, and AIM-100, respectively.

\section{Synthesis of $\mathrm{MoS}_{2}-\mathrm{Al}$}

$\mathrm{MoS}_{2}$-Al was prepared in much the same way as AIM-60, except for using $\gamma-\mathrm{Al}_{2} \mathrm{O}_{3}$ instead of $\mathrm{NU}-1000$.

\section{Synthesis of $\mathrm{MoS}_{2} / \gamma-\mathrm{Al}_{2} \mathrm{O}_{3}$}

For comparison, $\mathrm{MoS}_{2} / \gamma-\mathrm{Al}_{2} \mathrm{O}_{3}$ was also prepared by the incipient wetness coimpregnation method, according to the previous literature. ${ }^{38}$ Typically, ammonium molybdate $(50.8 \mathrm{mg})$ was added to deionized water $(6.50 \mathrm{~mL})$ and stirred until it was dissolved. $\gamma-\mathrm{Al}_{2} \mathrm{O}_{3}(5.00 \mathrm{~g})$ was quickly added into the above solution, evenly stirred, sealed with plastic wrap, and sonicated for $15 \mathrm{~min}$. The solution was kept at room temperature for $12 \mathrm{~h}$, then dried in a $110{ }^{\circ} \mathrm{C}$ oven for $10 \mathrm{~h}$, and finally calcined in a muffle furnace at $500{ }^{\circ} \mathrm{C}$ for $2 \mathrm{~h}$. The obtained sample was first reduced in $10 \% \mathrm{H}_{2}$ in $\mathrm{Ar}$ and then presulfided in $2 \% \mathrm{H}_{2} \mathrm{~S}$ in $\mathrm{N}_{2}$, as shown in Fig. S2 (ESI $\dagger$ ). The final sample obtained was labeled $\mathrm{MoS}_{2} / \gamma-\mathrm{Al}_{2} \mathrm{O}_{3}$.

\section{Synthesis of $\mathrm{MoS}_{2} / \gamma-\mathrm{Al}_{2} \mathrm{O}_{3}(\mathrm{H})$}

$\mathrm{MoS}_{2} / \gamma-\mathrm{Al}_{2} \mathrm{O}_{3}(\mathrm{H})$ was prepared in much the same way as $\mathrm{MoS}_{2} /$ $\gamma-\mathrm{Al}_{2} \mathrm{O}_{3}$, except it was presulfided in $2 \% \mathrm{H}_{2} \mathrm{~S}$ in $\mathrm{N}_{2}$ at $360{ }^{\circ} \mathrm{C}$ for $4 \mathrm{~h}$.

\section{Hydrodesulfurization of dibenzothiophene}

The HDS of DBT was carried out in a $100 \mathrm{~mL}$ high-pressure reactor. Typically, AIM- $X$ catalyst $(0.10 \mathrm{~g})$ was loaded in the reactor. A $15 \mathrm{~mL} n$-hexane solution with $0.58 \mathrm{wt} \% \mathrm{DBT}$ (sulfur content of $1000 \mu \mathrm{g} \mathrm{g}^{-1}$ ) was poured into the reactor. The HDS reaction was performed under the follow conditions: pressure of 3.0 MPa, temperature of $250{ }^{\circ} \mathrm{C}$, stirring rate of $600 \mathrm{rpm}$, reaction time of $4 \mathrm{~h}$. A final pressure range between 5.5 and 6.5 MPa inside the reactor was reached. The DBT contents before and after the reaction were measured on a Shimadzu GC-2014C gas chromatograph, equipped with a DB-WAX capillary column (length $30 \mathrm{~m}$, diameter $0.25 \mathrm{~mm}$ ) and an auto injector. The DBT conversion was calculated according to the following equation:

$$
\Delta c=\frac{c_{0}-c_{1}}{c_{0}} \times 100 \%
$$

where $\Delta c$ is the DBT conversion, and $c_{0}$ and $c_{1}$ are DBT concentration before and after the reaction, respectively.

According to the literature, ${ }^{3,39,40}$ the HDS of DBT is considered to follow a quasi-first-order kinetic model, and the reaction rate constant $\left(k_{\mathrm{HDS}}, \mathrm{mol} \mathrm{g}^{-1} \mathrm{~h}^{-1}\right)$ could be calculated with the following equation: 


$$
k_{\mathrm{HDS}}=\frac{F}{M} \ln \left(\frac{1}{1-x}\right)
$$

where $M$ is the catalyst mass (g), $F$ is the molar feed rate of DBT $\left(\mathrm{mol} \mathrm{h}^{-1}\right)$, and $x$ is the conversion rate of DBT, and $k_{\mathrm{HDS}}$ is the reaction rate constant of HDS in $\mathrm{mol} \mathrm{g}^{-1} \mathrm{~h}^{-1}$.

The HDS reaction was performed in succession using the same catalyst to evaluate the recyclability of the AIM- $X$ catalyst. After each HDS reaction, the AIM- $X$ catalyst was isolated via centrifugation (9000 rpm, $5 \mathrm{~min}$ ), washed twice with ethanol, and dried in a vacuum oven at $60{ }^{\circ} \mathrm{C}$ for $3 \mathrm{~h}$.

\section{Method and instruments}

Powder X-ray diffraction (PXRD) patterns were obtained on an X-ray diffractometer (Rigaku MiniFlex600) with $\mathrm{Cu} \mathrm{K} \alpha$ radiation. Nitrogen sorption isotherms were collected on a Micrometrics ASAP 2020M volumetric gas adsorption analyzer at $77 \mathrm{~K}$. Before measurement, samples were degassed at $150{ }^{\circ} \mathrm{C}$ for $10 \mathrm{~h}$. The surface morphology of the samples was analyzed by scanning electron microscopy (SEM) (FEI Nanosem 430, Hitachi S-4800), energy dispersion spectra and field emission transmission electron microscopy (TEM) (FEI-Tecnai, G2F-20). The elemental contents in the samples were collected on an ICP-OES spectrometer. Thermogravimetric analysis (TGA) data were collected by a thermogravimetric analyzer (TG-8121), at a test temperature is $30-600{ }^{\circ} \mathrm{C}$ with a heating rate of $10{ }^{\circ} \mathrm{C} \mathrm{min}{ }^{-1}$ under Ar. The surface composition and chemical status were studied using X-ray photoelectron spectroscopy (XPS) employing a ThermoFisher EscaLab 250Xi spectrometer with $\mathrm{Al} \mathrm{K \alpha}$ $(1486.6 \mathrm{eV})$. The calibration of the spectra binding energy was performed with the C1s peak of the aliphatic carbons at $284.8 \mathrm{eV}$. Fourier transform infrared (FT-IR) spectra were measured on a Bruker TENSOR 27 FT-IR spectrometer at $273 \mathrm{~K}$ and the spectra were collected in the spectral window of $1000-4000 \mathrm{~cm}^{-1}$ at a resolution of $1 \mathrm{~cm}^{-1}$.

\section{Results and discussion}

\section{Synthesis and characterization of AIM-X}

Using $\mathrm{Mo}(\mathrm{CO})_{6}$ and $\mathrm{H}_{2} \mathrm{~S}$ as molybdenum source and sulfur source, respectively, the synthesized NU-1000 was functionalized by ALD. One ALD $\mathrm{MoS}_{2}$ cycle consists of four steps: $\mathrm{Mo}(\mathrm{CO})_{6}$ pulse, $\mathrm{N}_{2}$ purging, $\mathrm{H}_{2} \mathrm{~S}$ pulse, and $\mathrm{N}_{2}$ purging (Fig. S3, ESI $\dagger$ ). Due to the fact that the AIM-60 catalyst had the highest catalytic performance in the HDS experiment of DBT, a series of characterizations was carried out with AIM-60 as the representative. The synthesized NU-1000 and AIM-60 were firstly characterized by PXRD. As shown in Fig. 1, the PXRD pattern of AIM-60 confirms that NU-1000 maintains its crystallinity after molybdenum sulfide functionalization. Due to the low Mo loading in the AIM-60 catalyst, there is no characteristic peak of molybdenum species in the PXRD pattern. For comparison, we also synthesized $\gamma-\mathrm{Al}_{2} \mathrm{O}_{3}$ supported catalysts according to the literature (Fig. S4, ESI $\dagger$ ). ${ }^{38}$

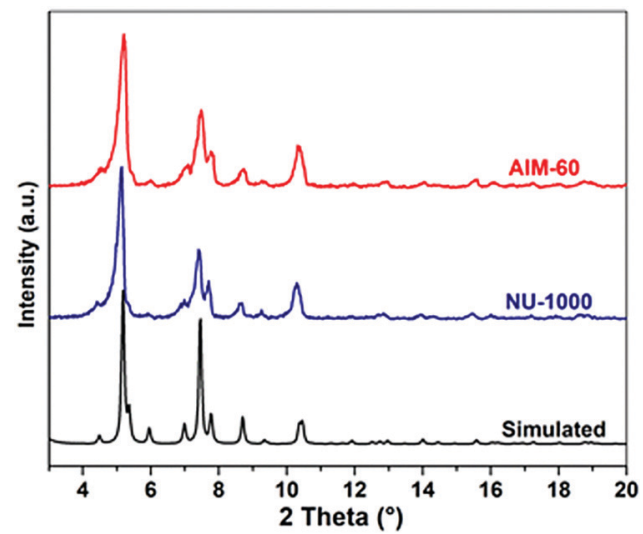

Fig. 1 PXRD patterns of AIM-60, NU-1000, and the simulated pattern of NU-1000 from crystallographic data.

The pore structure of the synthesized AIM-60 was analyzed using a nitrogen physical adsorption and desorption isotherm. As shown in Fig. 2a, the isotherm of as-synthesized NU-1000 has obvious H1-type hysteresis loops in the relative pressure range of $0.2-0.3$, indicating the existence of an obvious mesoporous structure. After incorporation of $\mathrm{MoS}_{2}$, the hysteresis loop moved to a smaller pressure range, indicating that the diameter of the mesopore of NU-1000 decreased and the adsorption amount also decreased significantly. When introducing $\mathrm{MoS}_{2}$ into $\mathrm{Al}_{2} \mathrm{O}_{3}$ by the impregnation method, its specific surface area was also significantly reduced. From the pore size distribution in Fig. 2b, the most probable pore size distribution of the investigated samples decreases in the order of NU-1000 > AIM-60, and these declines are attributed to deposition of active metals. Details of the changes in pore diameter distribution, specific surface area and ICP-OES results are summarized in Table 1. By calculation from the ICP-OES data, the S/Mo atomic ratio of the synthesized AIM-60 is close to 2, which is proof of the formation of $\mathrm{MoS}_{2}$. The specific surface area and the pore diameter of AIM-60 are much higher than those of $\mathrm{MoS}_{2} / \gamma-\mathrm{Al}_{2} \mathrm{O}_{3}$ with the same loading, indicating that AIM-60 has a better adsorption effect and thus could improve its HDS catalytic activity. Fig. S5 (ESI $\dagger$ ) shows the isotherms of AIM30, AIM-60 and AIM-90 in nitrogen adsorption and desorption. According to the IUPAC classification, all of the isotherms exhibit type IV characteristic. There are significant hysteresis loops in all the isotherms of AIM-30, AIM-60 and AIM-90, indicating a mesoporous nature. The ICP-OES results for AIM$X$ are shown in Fig. S6 (ESI $\dagger$ ).

Through infrared spectrum analysis, the binding sites of $\mathrm{MoS}_{2}$ and NU-1000 in the catalyst were revealed, and the obtained spectrum is shown in Fig. S7 (ESI $\dagger$ ). The characteristic bands detected at 3673 and $3655 \mathrm{~cm}^{-1}$ are attributed to node bridges in the combination of $\mu_{3}-\mathrm{OH}$, terminal $\mathrm{OH}$ and terminal $\mathrm{OH}_{2}$ groups, consistent with previous reports on NU1000 . $^{33-36}$ Compared with NU-1000, the peak value of AIM-60 at $3674 \mathrm{~cm}^{-1}$ was significantly reduced. These data seem to confirm the hypothesis that the growth of molybdenum sulfide initially occurred by reacting with the hydroxide and 

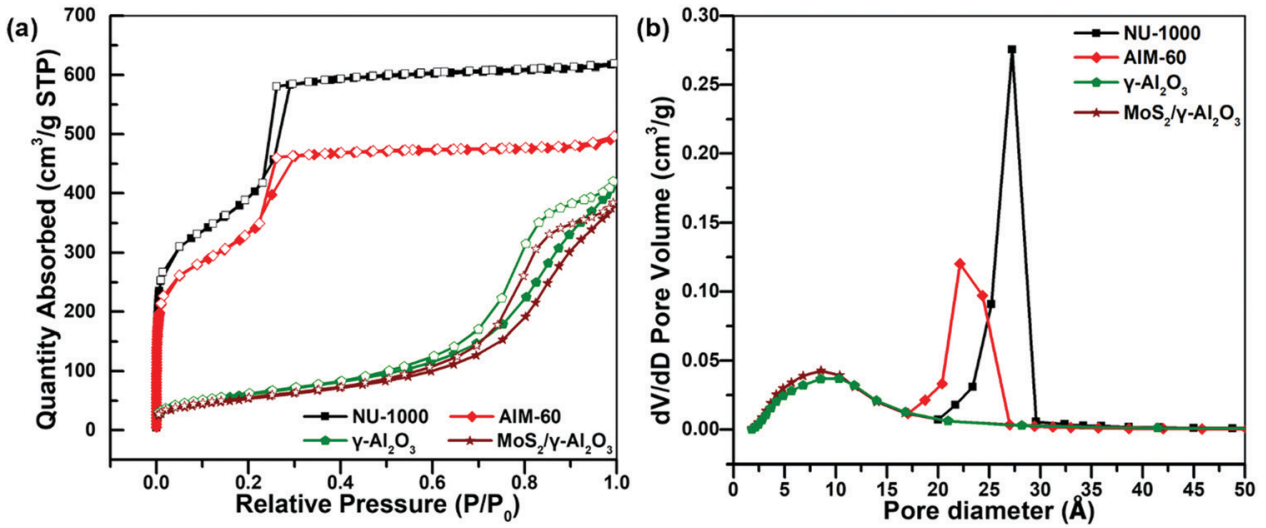

Fig. 2 (a) $\mathrm{N}_{2}$ physical adsorption-desorption isotherms of the synthesized samples at $77 \mathrm{~K}$. (b) Pore size distribution of the synthesized samples.

Table 1 Textural properties of the synthesized AIM-60 and $\mathrm{MoS}_{2} / \gamma-\mathrm{Al}_{2} \mathrm{O}_{3}$

\begin{tabular}{lclrll}
\hline Samples & $S_{\text {BET }}, \mathrm{m}^{2} \mathrm{~g}^{-1}$ & $V_{\mathrm{p}}, \mathrm{cm}^{3} \mathrm{~g}^{-1}$ & $D_{\text {ave }}, \AA$ & $\mathrm{Mo}^{a}, \mathrm{wt} \%$ & $\mathrm{~S}^{a}, \mathrm{wt} \%$ \\
\hline $\mathrm{NU}-1000$ & 1707 & 0.95 & 27.2 & - & - \\
$\mathrm{AIM}-60$ & 1073 & 0.75 & 24.1 & 0.552 & 0.366 \\
$\gamma-\mathrm{Al}_{2} \mathrm{O}_{3}$ & 225 & 0.60 & 10.3 & - & - \\
$\mathrm{MoS}_{2} / \gamma-\mathrm{Al}_{2} \mathrm{O}_{3}$ & 198 & 0.55 & 9.8 & 0.531 & 0.316
\end{tabular}

${ }^{a}$ Determined by means of ICP-OES.

water ligands of the $\mathrm{Zr}_{6}$ node in NU-1000. In addition, according to the pore size distribution (Fig. 2b), the pore size is reduced from 27 to $24 \AA$, which indicates the growth of molybdenum sulfide in NU-1000.

In order to study the morphology and particle size distribution of NU-1000, AIM-60, $\gamma-\mathrm{Al}_{2} \mathrm{O}_{3}$ and $\mathrm{MoS}_{2} / \gamma-\mathrm{Al}_{2} \mathrm{O}_{3}$, we conducted SEM analysis and the results obtained are shown in Fig. 3. The results clearly show that NU-1000 has clear spindle form and $\gamma-\mathrm{Al}_{2} \mathrm{O}_{3}$ is a block-shaped crystal. After adding a relatively low $\mathrm{MoS}_{2}$ content, the surface of the AIM-60 and $\mathrm{MoS}_{2} / \gamma-\mathrm{Al}_{2} \mathrm{O}_{3}$ samples became rough, and the particle size did not change significantly. Generally, a larger surface area can achieve better dispersibility. The particle size distribution of the AIM-60 catalyst was more uniform than that of the corresponding $\mathrm{MoS}_{2} / \gamma-\mathrm{Al}_{2} \mathrm{O}_{3}$. And the $\mathrm{N}_{2}$ physical adsorption analysis proved that AIM-60 has a significantly larger surface area than $\mathrm{MoS}_{2} / \gamma-\mathrm{Al}_{2} \mathrm{O}_{3}$. In addition, the SEM-EDS curve in Fig. S8 (ESI $\dagger$ ) clearly shows that NU-1000 was successfully modified by $\mathrm{MoS}_{2}$. A typical TEM image of AIM-60 is shown in Fig. 3e, and the corresponding EDX spectra demonstrate that AIM-60 contains uniformly distributed elements of $\mathrm{Zr}$, Mo, and S (Fig. 3f-h). The overlap between Mo and $\mathrm{S}$ indicates the formation of a metallic sulfide, rather than a separate mixture of Mo and S. As shown in the inset of Fig. 3i, the atomic ratio of $\mathrm{Mo} / \mathrm{S}$ is calculated to be approximately $1: 2$, which is related to the stoichiometric composition of $\mathrm{MoS}_{2}$.

In order to investigate the thermal stability of the synthesized catalysts, TGA was carried out in an Ar atmosphere. As shown in Fig. 4a, the TG curves of AIM-60 and NU-1000 are similar, and they decompose above $400{ }^{\circ} \mathrm{C}$, showing that NU-1000 has excellent thermal stability, and it can maintain a relatively complete skeleton structure at $400{ }^{\circ} \mathrm{C}$. However, when the temperature exceeded $400{ }^{\circ} \mathrm{C}$, the mass of the catalyst began to decline rapidly, which may be caused by the collapse of the skeleton of NU-1000 and the destruction of the organic ligands. Significantly, AIM-60 had a residual ash mass of $39.17 \%$ at $600{ }^{\circ} \mathrm{C}$, while $\mathrm{NU}-1000$ had a residual ash mass of $37.20 \%$. The difference in mass fraction might be caused by $\mathrm{MoS}_{2}$ deposition in AIM-60 relative to NU-1000. After thermogravimetric analysis, as shown in Fig. $4 \mathrm{~b}$, the PXRD patterns of AIM-60 and NU-1000 showed the characteristic peaks of $\mathrm{ZrO}_{2}$ at $30.1^{\circ}, 34.9^{\circ}, 50.2^{\circ}, 59.7^{\circ}, 62.6^{\circ}$ and $73.9^{\circ}\left(\mathrm{ZrO}_{2}, \mathrm{PDF} \# 49-1642\right)$.

In order to better understand the chemical state, sulfurization degree (SD) and surface composition of the active metal of the catalysts, XPS analysis of AIM-60 and $\mathrm{MoS}_{2} / \gamma-\mathrm{Al}_{2} \mathrm{O}_{3}$ was conducted. As shown in Fig. 5, for S2p, peaks at around $162.28 \mathrm{eV}$ and $163.43 \mathrm{eV}$ can be assigned to $\mathrm{S}^{2-}$ and some terminal $\mathrm{S}_{2}{ }^{2-}$, peaks at around $164.58 \mathrm{eV}$ and $165.88 \mathrm{eV}$ can be attributed to the bridging $\mathrm{S}_{2}{ }^{2-}$, and the peak of $\mathrm{SO}_{4}{ }^{2-}$ is located near $169.3 \mathrm{eV}$. During the experiment, $\mathrm{S}^{2-}$ was inevitably oxidized to form $\mathrm{S}_{2}{ }^{2-}$ and $\mathrm{SO}_{4}{ }^{2-}$ due to contact with air. ${ }^{41-43}$ By Gaussian fitting, the Mo 3d spectrum can be decomposed into two double peaks of the spin orbit, namely Mo $3 \mathrm{~d}_{5 / 2}$ and Mo $3 d_{3 / 2}$. The binding energies of Mo $3 d_{5 / 2}$ and Mo $3 d_{3 / 2}$ in the $\mathrm{MoS}_{2}\left(\mathrm{Mo}^{4+}\right)$ phase are $228.0 \mathrm{eV}$ and $232.0 \mathrm{eV}$, respectively. The binding energies of Mo $3 \mathrm{~d}_{5 / 2}$ and Mo $3 \mathrm{~d}_{3 / 2}$ of $\mathrm{MoO}_{x} \mathrm{~S}_{y}\left(\mathrm{Mo}^{5+}\right)$ mesophase are $230.9 \mathrm{eV}$ and $234.2 \mathrm{eV}$, respectively. The binding energies of $\mathrm{Mo} 3 \mathrm{~d}_{5 / 2}$ and $\mathrm{Mo} 3 \mathrm{~d}_{3 / 2}$ in $\mathrm{MoO}_{3}\left(\mathrm{Mo}^{6+}\right)$ phase are $232.8 \mathrm{eV}$ and $235.8 \mathrm{eV}$, respectively. The SD of a Mo-based sulfide catalyst is defined as the atomic ratio of $\mathrm{Mo}^{4+}$ to the sum of $\mathrm{Mo}^{4+}, \mathrm{Mo}^{5+}$ and $\mathrm{Mo}^{6+}$, wherein $\mathrm{Mo}^{4+}, \mathrm{Mo}^{5+}$ and $\mathrm{Mo}^{6+}$ represent $\mathrm{MoS}_{2}\left(\mathrm{Mo}^{4+}\right), \mathrm{MoO}_{x} \mathrm{~S}_{y}\left(\mathrm{Mo}^{5+}\right)$ and $\mathrm{MoO}_{3}\left(\mathrm{Mo}^{6+}\right)$ phases, respectively. ${ }^{44,45}$ The XPS fitting results in Table 2 show that the Mo SDs of AIM-60 and $\mathrm{MoS}_{2} / \gamma-\mathrm{Al}_{2} \mathrm{O}_{3}$ are $40.82 \%$ and $7.22 \%$, respectively, suggesting that AIM-60 should show higher HDS activity.

\section{Catalytic performances of AIM- $X$ catalysts}

Studies have shown that among the different S-containing molecules in feedstocks, dibenzothiophene is considered a very difficult molecule to desulfurize. ${ }^{3,40}$ Therefore, the hydrodesulfurization 

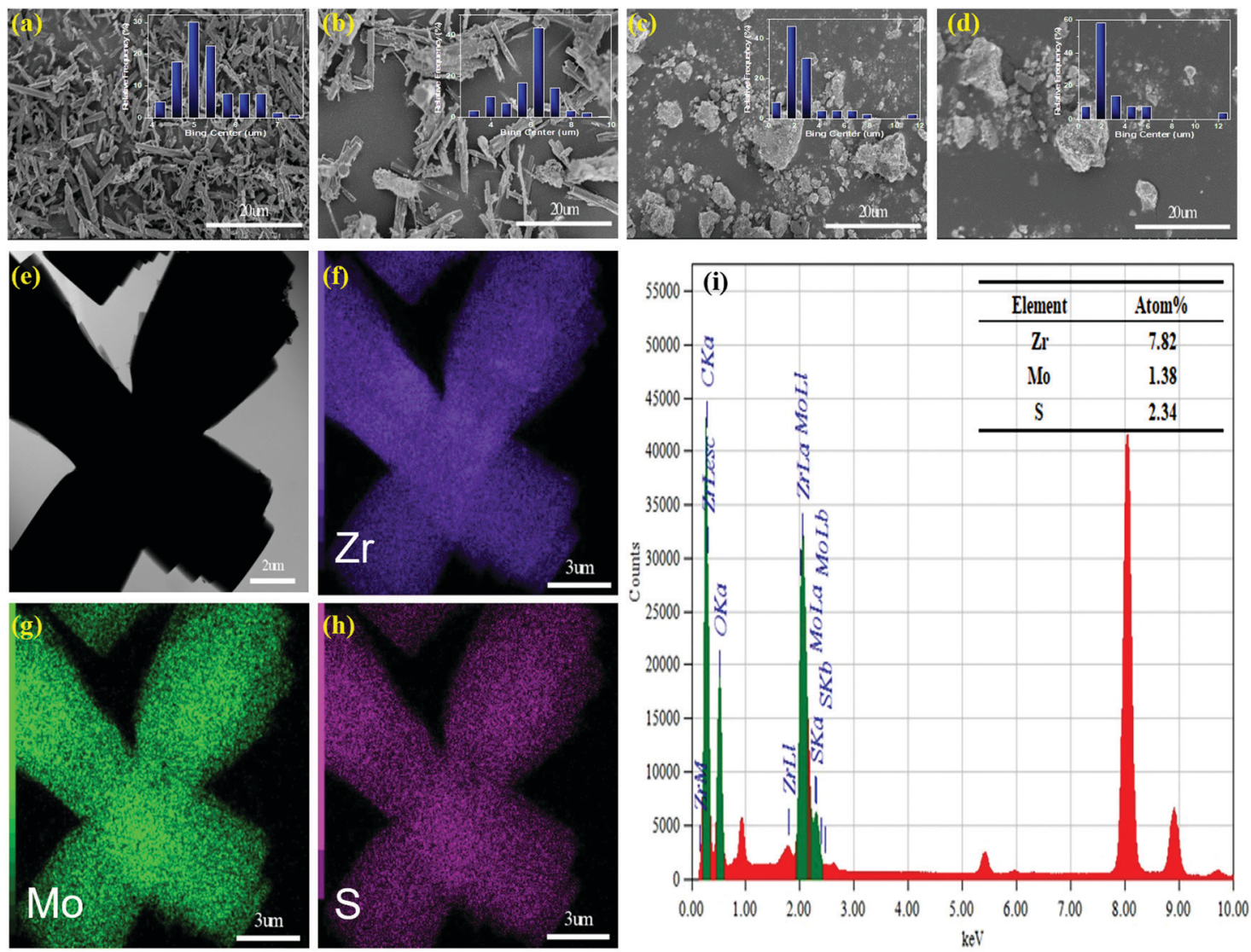

Fig. 3 SEM images of the as-prepared NU-1000 (a), AIM-60(b), $\gamma-\mathrm{Al}_{2} \mathrm{O}_{3}(\mathrm{c})$ and $\mathrm{MoS}_{2} / \gamma-\mathrm{Al}_{2} \mathrm{O}_{3}$. (d) TEM image of the as-prepared AIM-60 (e), and the corresponding elemental mappings of (f) $\mathrm{Zr}$, (g) Mo, and (h) S, EDX spectra (i), and atomic percentage (inset).
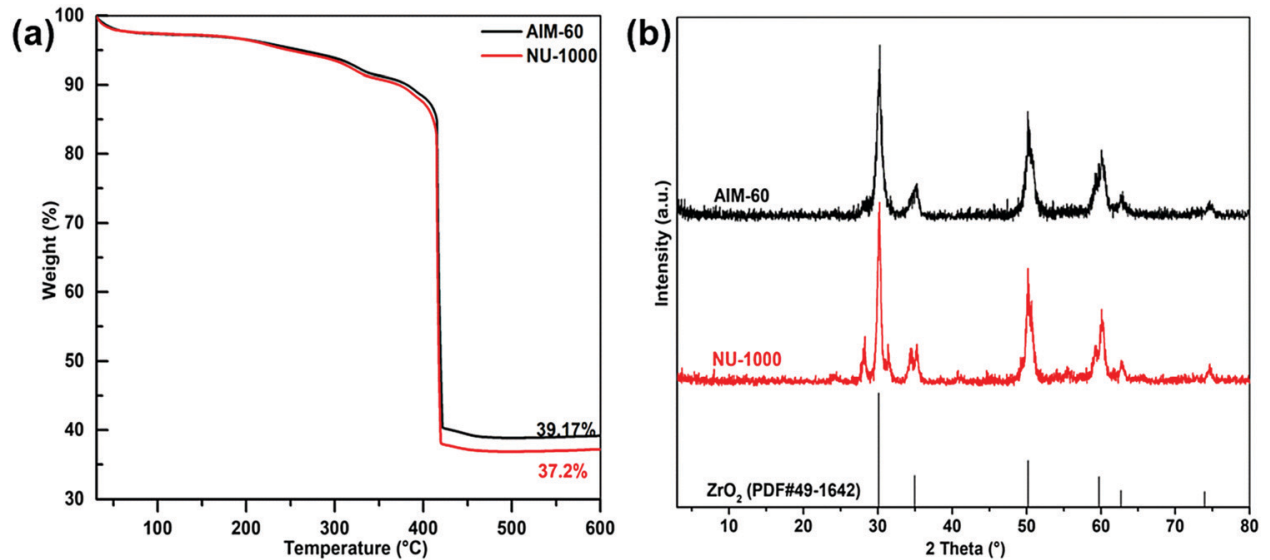

Fig. 4 (a) Thermogravimetric curves for NU-1000 (red) and AIM-60 (black) in Ar. (b) PXRD patterns of AIM-60 and NU-1000 after thermogravimetric treatment.

reaction of dibenzothiophene is often used as a model reaction when evaluating the catalytic performance of hydrodesulfurization catalysts. Considering that the addition of an appropriate amount of $\mathrm{MoS}_{2}$ can regulate the physical and chemical properties of the catalyst, we prepared an AIM- $X$ series of catalysts with different deposition cycles through ALD. Here, the HDS activities of the investigated AIM- $X$ series catalysts and $\mathrm{MoS}_{2} / \gamma-\mathrm{Al}_{2} \mathrm{O}_{3}$ were evaluated at $180,200,230$ and $250{ }^{\circ} \mathrm{C}$ and the DBT conversions are shown in Fig. 6.

As shown in Fig. 6a, the conversions of DBT clearly show that the activities of the investigated catalysts increased with an increase in temperature. At all temperatures investigated, the conversions of the catalysts are in the order of $\mathrm{MoS}_{2} / \gamma-\mathrm{Al}_{2} \mathrm{O}_{3}$ $<\mathrm{MoS}_{2}-\mathrm{Al}<\mathrm{MoS}_{2} / \gamma-\mathrm{Al}_{2} \mathrm{O}_{3}(\mathrm{H})<\mathrm{AIM}-30<\mathrm{AIM}-90<\mathrm{AIM}-60$. 

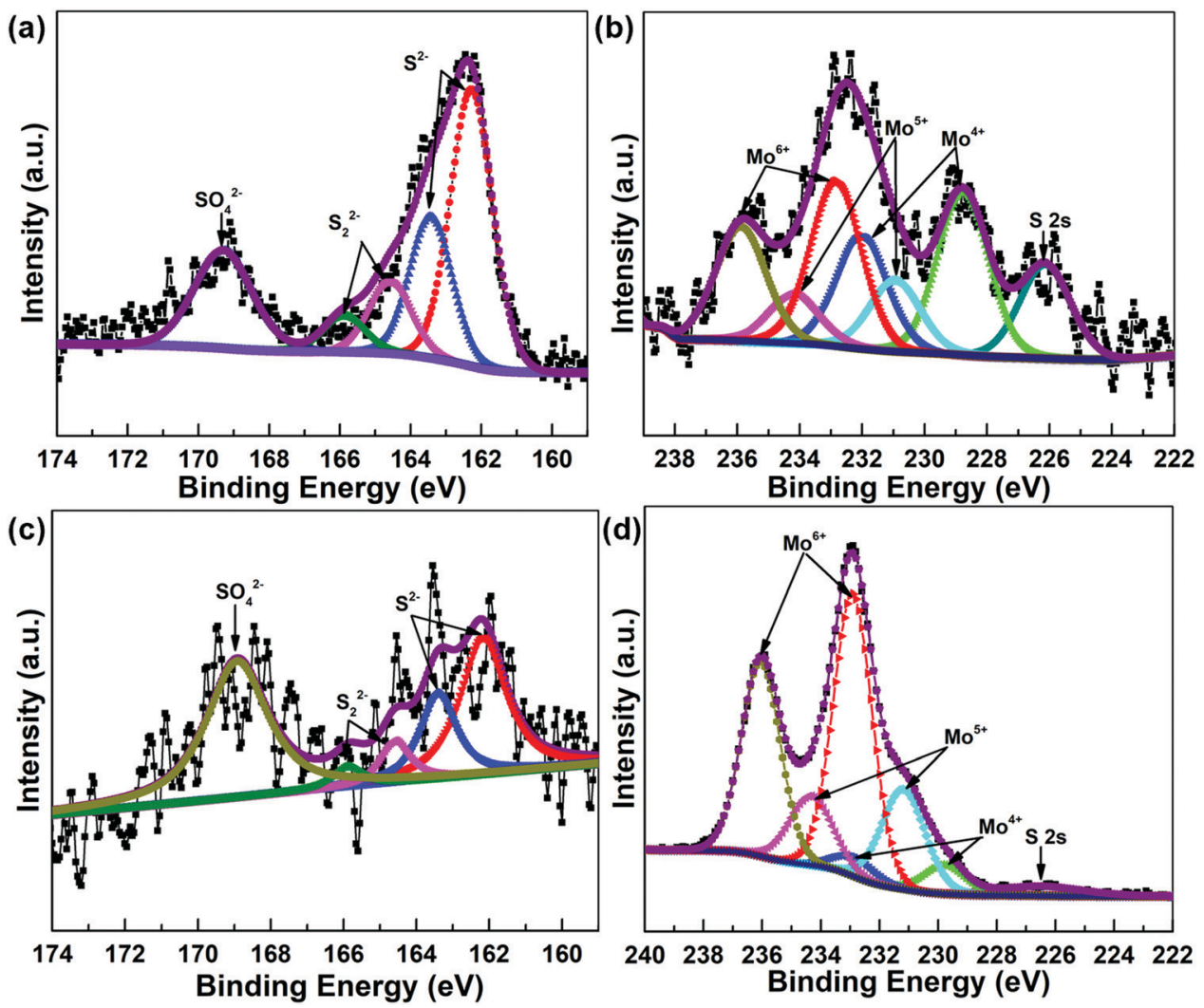

Fig. 5 XPS spectra of AIM-60 and $\mathrm{MoS}_{2} / \gamma-\mathrm{Al}_{2} \mathrm{O}_{3}$ catalysts: S $2 p$ spectra deconvolution of AIM-60 (a) and $\mathrm{MoS}_{2} / \gamma-\mathrm{Al}_{2} \mathrm{O}_{3}$ (c), Mo $3 \mathrm{~d}$ spectra deconvolution of $\mathrm{AIM}-60$ (b) and $\mathrm{MoS}_{2} / \gamma-\mathrm{Al}_{2} \mathrm{O}_{3}(\mathrm{~d})$.

Table 2 XPS characterization results of the AIM-60 and $\mathrm{MoS}_{2} / \gamma-\mathrm{Al}_{2} \mathrm{O}_{3}$ catalysts

\begin{tabular}{lcccc}
\hline & \multicolumn{2}{c}{ The content of Mo species (\%) } & \\
\cline { 2 - 4 } Catalysts & $\mathrm{MoS}_{2}$ & $\mathrm{MoO}_{x} \mathrm{~S}_{y}$ & $\mathrm{MoO}_{3}$ & Mo $_{\text {sulfidation }}{ }^{a}(\%)$ \\
\hline $\mathrm{AIM} 60$ & 40.82 & 17.89 & 41.29 & 40.82 \\
$\mathrm{MoS}_{2} / \gamma-\mathrm{Al}_{2} \mathrm{O}_{3}$ & 7.22 & 26.41 & 66.37 & 7.22 \\
${ }^{a} \mathrm{Mo}_{\text {sulfidation }}$ defined as $\mathrm{Mo}^{4+} /\left(\mathrm{Mo}^{4+}+\mathrm{Mo}^{5+}+\mathrm{Mo}^{6+}\right) \times 100 \%$.
\end{tabular}

The DBT conversions of the AIM- $X$ catalysts increased from $65.40 \%$ for AIM-30 to $86.74 \%$ for AIM-60 and then decreased to
$70.03 \%$ for AIM-100 as the number of ALD cycles increased from 30 to 100 (Fig. 6b). In order to test the stability of the catalyst, AIM-60 was recycled after the reaction and the HDS reaction of DBT was performed under the same conditions. As shown in Fig. 6c, the conversion rate was still higher than $80 \%$ after 5 cycles. The PXRD of the AIM- $X$ samples remained intact after the hydrodesulfurization reaction (Fig. S9, ESI $\dagger$ ), indicating the high stability of the AIM- $X$ catalysts.

Based on the results above, the high catalytic efficiency of AIM-60 is attributed to its unique physicochemical properties. The $\mathrm{N}_{2}$ physical adsorption analysis of the catalyst shows that
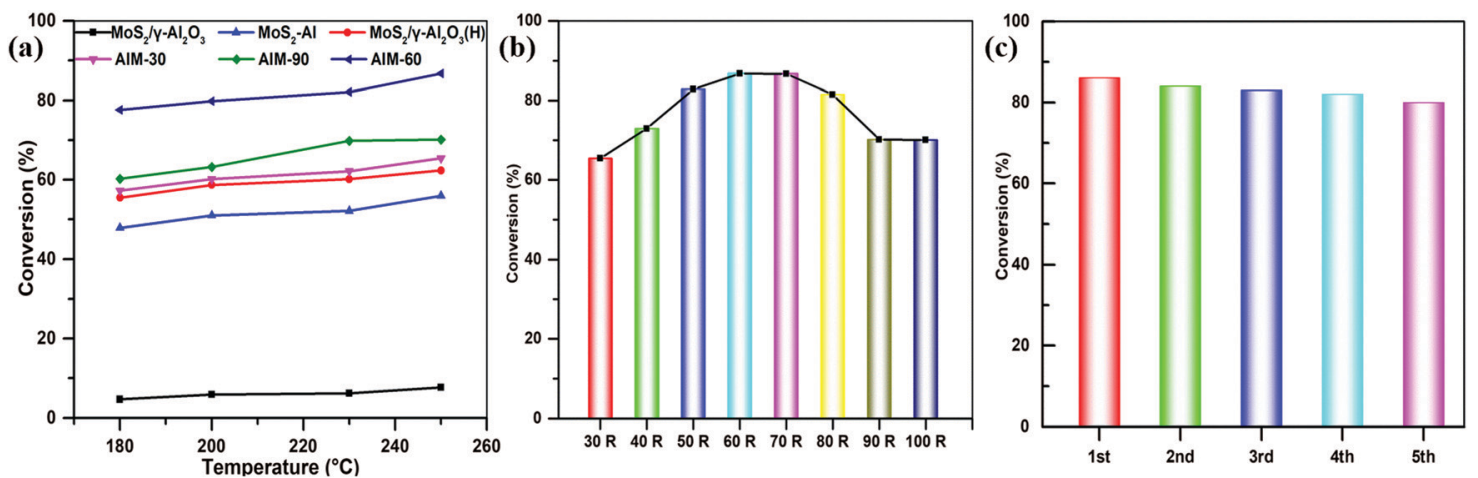

Fig. 6 (a) Dibenzothiophene conversions over the investigated catalysts at different reaction temperatures. (b) HDS activity comparison between different AIM-X catalysts at $250^{\circ} \mathrm{C}$. (c) Reusability of the AIM-60 catalyst at $250{ }^{\circ} \mathrm{C}$. 


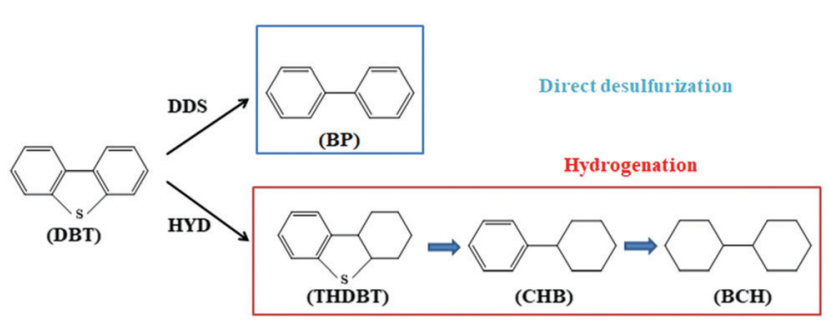

Fig. 7 HDS of DBT reaction pathways over catalysts.

the specific surface area and pore size of AIM-60 are much larger than those of $\mathrm{MoS}_{2} / \gamma-\mathrm{Al}_{2} \mathrm{O}_{3}$, which results in a better and more uniform distribution of active nanometals. In addition, XPS analysis shows that the AIM- 60 catalyst provided a higher degree of sulfidation than $\mathrm{MoS}_{2} / \gamma-\mathrm{Al}_{2} \mathrm{O}_{3}$ with the same loading, which means that it has active sites with higher adsorption affinity, which in turn makes the DBT more effectively desulfurized. Consequently, a better desulfurization effect can be achieved on the active site of the catalyst AIM-60. Compared with a conventional catalyst supported on $\gamma-\mathrm{Al}_{2} \mathrm{O}_{3}$, all these factors improve the HDS catalytic efficiency of AIM-60. It is worth noting that the catalyst has an excellent cycle stability, with negligible loss of catalytic activity.

\section{HDS reaction mechanisms}

Based on previous research results, ${ }^{16,46}$ there are two possible pathways for the HDS of DBT, as shown in Fig. 7. The first is a direct desulfurization (DDS) pathway and the second is a hydrodesulfurization (HYD) pathway. Intermediates, such as tetrahydrodibenzothiophene (THDBT), cyclohexyl benzene (CHB) and bicyclohexyl (BCH), are considered to be products of the HYD pathway, and biphenyl (BP) is considered to be the product of the DDS pathway. At the identical conversion (10\%) of DBT, the HDS product distributions of AIM-60 and $\mathrm{MoS}_{2} / \gamma-\mathrm{Al}_{2} \mathrm{O}_{3}$ were compared, and the results are listed in Table 3. The $\mathrm{k}_{\mathrm{HDS}}$ of AIM-60 is much higher than that of $\mathrm{MoS}_{2} / \gamma-\mathrm{Al}_{2} \mathrm{O}_{3}$, indicating that AIM-60 has higher catalytic activity. In order to compare the contribution of DDS and HYD to the overall HDS of the two catalysts, it is appropriate to use the yield ratio of $\mathrm{BP} /(1-\mathrm{BP})$ to indicate the selectivity of the DDS/HYD route. As shown in Table 3, the DDS/HYD ratio of AIM-60 is 6.87, much higher than 1, indicating that AIM-60 is more inclined to the DDS pathway, while the ratio of $\mathrm{MoS}_{2} /$ $\gamma-\mathrm{Al}_{2} \mathrm{O}_{3}$ is 0.96 .

Table 3 HDS results for DBT on AIM-60 and $\mathrm{MoS}_{2} / \gamma-\mathrm{Al}_{2} \mathrm{O}_{3}$

\begin{tabular}{lllll}
\hline & & \multicolumn{3}{c}{ Product selectivity (\%) } \\
\cline { 4 - 5 } Samples & $k_{\mathrm{HDS}}{ }^{a}\left(10^{-5} \mathrm{~mol} \mathrm{~g}^{-1} \mathrm{~h}^{-1}\right)$ & $\mathrm{BP}$ & $\mathrm{CHB}$ & $\mathrm{DDS} / \mathrm{HYD}$ \\
\hline $\mathrm{AIM}-60$ & 5.72 & 87.3 & 12.7 & 6.87 \\
$\mathrm{MoS}_{2} / \gamma-\mathrm{Al}_{2} \mathrm{O}_{3}$ & 1.86 & 48.9 & 51.1 & 0.96 \\
$\mathrm{MoS}_{2}$-Al & 4.76 & 39.3 & 60.7 & 0.65 \\
\multicolumn{2}{l}{${ }^{a}$ Calculated with DBT conversion at about } & & &
\end{tabular}

\section{Conclusions}

In summary, we have developed a method to prepare a hydrodesulfurization catalyst by loading $\mathrm{MoS}_{2}$ in NU-1000 through ALD, using molybdenum hexacarbonyl and hydrogen sulfide as the molybdenum source and sulfur source, respectively. The synthesized AIM- $X$ composites exhibited excellent HDS activity and the conversions of the AIM- $X$ series of catalysts were much higher than that of $\mathrm{MoS}_{2} / \gamma-\mathrm{Al}_{2} \mathrm{O}_{3}$. The conversion rate of AIM-60 reached its highest, $86.74 \%$, at $250{ }^{\circ} \mathrm{C}$ and $3 \mathrm{MPa}$. Due to the large number of sources of transition metal precursors, we believe that ALD can be used to deposit other metal sulfides in other MOFs for other catalytic processes, such as dehydrogenation or deoxygenation. The AIM- $X$ series catalysts provide a new prospect for the development of ecologically friendly HDS processes, which can reduce hydrogen consumption during desulfurization and maintain excellent desulfurization activity and high stability.

\section{Author contributions}

L. Yu and Q. Zhang performed the experiments; L. Yu contributed to write the manuscript; L. Yu and W. G. Cui analyzed the data; Y. Shen, Z. F. Li, and W. G. Cui contributed to revising the manuscript; and T. L. Hu conceived the study, designed and supervised the overall project, and wrote the manuscript.

\section{Conflicts of interest}

There are no conflicts to declare.

\section{Acknowledgements}

This work was financially supported by the National Natural Science Foundation of China (21673120 and 21421001), the Natural Science Foundation of Tianjin (20JCYBJC01330) and the Fundamental Research Funds for the Central Universities, Nankai University (63196005).

\section{References}

1 W. Zhou, L. Yang, L. Liu, Z. Chen, A. Zhou, Y. Zhang, X. He, F. Shi and Z. Zhao, Appl. Catal., B, 2020, 268, 118428.

2 X. Chen, M. Zhang, Y. Wei, H. Li, J. Liu, Q. Zhang, W. Zhu and H. Li, Inorg. Chem. Front., 2018, 5, 2478-2485.

3 A. López-Benítez, G. Berhault and A. Guevara-Lara, Appl. Catal., B, 2017, 213, 28-41.

4 G. Yang, J. Han, Z. Qiu, X. Chen, Z. Feng and J. Yu, Inorg. Chem. Front., 2020, 7, 1975-1980.

5 A. N. Varakin, A. V. Mozhaev, A. A. Pimerzin and P. A. Nikulshin, Appl. Catal., B, 2018, 238, 498-508.

6 H. Li, J. Liu, J. Li, Y. Hu, W. Wang, D. Yuan, Y. Wang, T. Yang, L. Li, H. Sun, S. Ren, X. Zhu, Q. Guo, X. Wen, Y. Li and B. Shen, ACS Catal., 2017, 7, 4805-4816.

7 G. Ye, H. Qi, W. Zhou, W. Xu and Y. Sun, Inorg. Chem. Front., 2019, 6, 1267-1274. 
8 Z. Cao, X. Zhang, R. Guo, S. Ding, P. Zheng, J. Fan, J. Mei, C. Xu and A. Duan, Chem. Eng. J., 2020, 400, 125886.

9 Y. Pan, M. Chen, M. Hu, M. Tian, Y. Zhang and D. Long, Appl. Catal., B, 2020, 262, 118266.

10 A. A. Toutov, M. Salata, A. Fedorov, Y. F. Yang, Y. Liang, R. Cariou, K. N. Betz, E. P. A. Couzijn, J. W. Shabaker, K. N. Houk and R. H. Grubbs, Nat. Energy, 2017, 2, 17008.

11 A. Alsalme, N. Alzaqri, A. Alsaleh, M. R. H. Siddiqui, A. Alotaibi, E. F. Kozhevnikova and I. V. Kozhevnikov, Appl. Catal., B, 2016, 182, 102-108.

12 R. Singh, D. Kunzru and S. Sivakumar, Appl. Catal., B, 2016, 185, 163-173.

13 A. Bodin, A. L. N. Christoffersen, C. F. Elkjaer, M. Brorson, J. Kibsgaard, S. Helveg and I. Chorkendorff, Nano Lett., 2018, 18, 3454-3460.

14 X. Liu, S. Ding, Q. Wei, Y. Zhou, P. Zhang and Z. Xu, Fuel, 2021, 285, 119039.

15 S. Shan, P. Yuan, W. Han, G. Shi and X. Bao, J. Catal., 2015, 330, 288-301.

16 C. Larabi, P. K. Nielsen, S. Helveg, C. Thieuleux, F. B. Johansson, M. Brorson and E. A. Quadrelli, ACS Catal., 2012, 2, 695-700.

17 W. G. Cui and T. L. Hu, Small, 2020, 16, 2003971.

18 Y. Shen, L. W. Bao, F. Z. Sun and T. L. Hu, Mater. Chem. Front, 2019, 3, 2363-2373.

19 W. G. Cui, T. L. Hu and X. H. Bu, Adv. Mater., 2020, 32, 1806445.

20 M. H. Yu, B. Space, D. Franz, W. Zhou, C. He, L. Li, R. Krishna, Z. Chang, W. Li, T. L. Hu and X. H. Bu, J. Am. Chem. Soc., 2019, 141, 17703-17712.

21 Y. L. Peng, J. Liu, H. F. Zhang, D. Luo and D. Li, Inorg. Chem. Front., 2018, 5, 1563-1569.

22 Y. Wang, Y. Wang, L. Zhang, C. S. Liu and H. Pang, Inorg. Chem. Front., 2019, 6, 2514-2520.

23 T. L. Hu, H. Wang, B. Li, R. Krishna, H. Wu, W. Zhou, Y. Zhao, Y. Han, X. Wang, W. Zhu, Z. Yao, S. Xiang and B. Chen, Nat. Commun., 2015, 6, 7328.

24 W. G. Cui, G. Y. Zhang, T. L. Hu and X. H. Bu, Coord. Chem. Rev., 2019, 387, 79-120.

25 Z. Li, A. W. Peters, V. Bernales, M. A. Ortuno, N. M. Schweitzer, M. R. DeStefano, L. C. Gallington, A. E. Platero-Prats, K. W. Chapman, C. J. Cramer, L. Gagliardi, J. T. Hupp and O. K. Farha, ACS Cent. Sci., 2017, 3, 31-38.

26 Z. Li, N. M. Schweitzer, A. B. League, V. Bernales, A. W. Peters, A. B. Getsoian, T. C. Wang, J. T. Miller, A. Vjunov, J. L. Fulton, J. A. Lercher, C. J. Cramer, L. Gagliardi, J. T. Hupp and O. K. Farha, J. Am. Chem. Soc., 2016, 138, 1977-1982.

27 L. C. Gallington, I. S. Kim, W. G. Liu, A. A. Yakovenko, A. E. Platero-Prats, Z. Li, T. C. Wang, J. T. Hupp, O. K. Farha, D. G. Truhlar, A. B. F. Martinson and K. W. Chapman, J. Am. Chem. Soc., 2016, 138, 13513-13516.
28 H. F. Barton, A. K. Davis and G. N. Parsons, ACS Appl. Mater. Interfaces, 2020, 12, 14690-14701.

29 Z. Li, A. W. Peters, J. Liu, X. Zhang, N. M. Schweitzer, J. T. Hupp and O. K. Farha, Inorg. Chem. Front., 2017, 4, 820-824.

30 S. Relijic, A. Broto-Ribas, C. Cuadrado-Collados, E. O. Jardim, D. Maspoch, I. Imaz and J. Silvestre-Albero, Chem. - Eur. J., 2020, 26, 1-11.

31 W. Zhang, J. Wang, L. Su, H. Chen, L. Zhang, L. Lin, X. Chen, J. Song and H. Yang, Sci. China: Chem., 2020, 63, 1315-1322.

32 A. W. Peters, Z. Li, O. K. Farha and J. T. Hupp, ACS Nano, 2015, 9, 8484-8490.

33 A. E. Platero-Prats, A. B. League, V. Bernales, J. Ye, L. C. Gallington, A. Vjunov, N. M. Schweitzer, Z. Li, J. Zheng, B. L. Mehdi, A. J. Stevens, A. Dohnalkova, M. Balasubramanian, O. K. Farha, J. T. Hupp, N. D. Browning, J. L. Fulton, D. M. Camaioni, J. A. Lercher, D. G. Truhlar, L. Gagliardi, C. J. Cramer and K. W. Chapman, J. Am. Chem. Soc., 2017, 139, 10410-10418.

34 W. G. Liu and D. G. Truhlar, Chem. Mater., 2017, 29, 8073-8081.

35 A. E. Platero-Prats, Z. Li, L. C. Gallington, A. W. Peters, J. T. Hupp, O. K. Farha and K. W. Chapman, Faraday Discuss., 2017, 201, 337-350.

36 P. C. Lemaire, D. T. Lee, J. Zhao and G. N. Parsons, ACS Appl. Mater. Interfaces, 2017, 9, 22042-22054.

37 H. Chen, P. Liao, M. L. Mendonca and R. Q. Snurr, J. Phys. Chem. C, 2018, 122, 12362-12368.

38 H. Sun, H. Sun, X. Zhang, Q. Yu, P. Zeng, Q. Guo, D. Wang, G. Wen, W. Zhang, S. He and B. Shen, ACS Catal., 2019, 9, 6613-6623.

39 X. Wang, C. Xiao, J. Mei, M. H. Alabsi, Y. Shi, Z. Zhao, A. Duan, K. W. Huang and C. Xu, ACS Appl. Mater. Interfaces, 2020, 12, 40404-40414.

40 X. Wang, J. Mei, Z. Zhao, P. Zheng, Z. Chen, D. Gao, J. Fu, J. Fan, A. Duan and C. Xu, ACS Catal., 2018, 8, 1891-1902.

41 Z. Liu, W. Han, D. Hu, H. Nie, Z. Wang, S. Sun, Z. Deng and Q. Yang, Catal. Sci. Technol., 2020, 10, 5218-5230.

42 W. Zhou, A. Zhou, Y. Zhang, C. Zhang, Z. Chen, L. Liu, Y. Zhou, Q. Wei and X. Tao, J. Catal., 2019, 374, 345-359.

43 T. A. Saleh and S. A. AL-Hammadi, Chem. Eng. J., 2021, 406, 125167.

44 X. Wang, P. Du, K. Chi, A. Duan, C. Xu, Z. Zhao, Z. Chen and H. Zhang, Catal. Today, 2017, 291, 146-152.

45 X. Wang, H. Fang, Z. Zhao, A. Duan, C. Xu, Z. Chen, M. Zhang, P. Du, S. Song, P. Zheng and K. Chi, RSC Adv., 2015, 5, 99706-99711.

46 K. Yang, X. Chen, J. Qi, Z. Bai, L. Zhang and C. Liang, J. Catal., 2019, 369, 363-371. 